\title{
Applications of Cu@C Nanoparticles in New Dye-Sensitized Solar Cells
}

\author{
Chang-Yu Liao, ${ }^{1}$ H. Paul Wang, ${ }^{1,2}$ F.-L. Chen, ${ }^{3}$ C.-H. Huang, ${ }^{1}$ and Y. Fukushima ${ }^{1}$ \\ ${ }^{1}$ Department of Environmental Engineering, National Cheng Kung University, Tainan City 70101, Taiwan \\ ${ }^{2}$ Sustainable Environment Research Center, National Cheng Kung University, Tainan City 70101, Taiwan \\ ${ }^{3}$ Department of Chemistry, National Cheng Kung University, Tainan City 70101, Taiwan
}

Correspondence should be addressed to H. Paul Wang, wanghp@mail.ncku.edu.tw

Received 6 October 2008; Accepted 22 January 2009

Recommended by Alan K. T. Lau

To enhance the efficiency of a newly developing dye-sensitized solar cell (DSSC), the Cu@C ( $\mathrm{Cu}$ size = 7 and 20 nm) core-shell nanoparticles-dispersed molten salt-conjugated electrolyte has been studied. Experimentally, the efficiencies $(\eta)$ of the DSSC are in the range of $2.70-4.09 \%$ with a short-circuit photocurrent density $\left(J_{\mathrm{SC}}\right)$ of $5.775-9.910 \mathrm{~mA} / \mathrm{cm}^{2}$. Interestingly, it is found that dispersion of $1 \%$ of the $\mathrm{Cu} @ \mathrm{C}(\mathrm{Cu}$ size $=7 \mathrm{~nm})$ nanoparticles in the molten salt-(1,2-dimethyl-3-propylimidazolium iodide (DMPII)) conjugated electrolyte results in an enhancement (about 11\%) of the $\eta(4.06 \%)$. Greater fractions (3-10\%) of the Cu@C nanoparticles dispersed in the molten salt cause a poor performance (lower $J_{S C}$ and $\eta$ ) of the DSSC possibly due to interference of the internal electron transportation routes in the DSSC by oxidation of $\mathrm{Cu}$ with $\mathrm{I}_{2}$ originally in the electrolyte.

Copyright () 2009 Chang-Yu Liao et al. This is an open access article distributed under the Creative Commons Attribution License, which permits unrestricted use, distribution, and reproduction in any medium, provided the original work is properly cited.

\section{Introduction}

Dye-sensitized solar cells with advantages of low manufacturing cost and comparable light-to-electricity conversion efficiency to conventional silicon-based photovoltaic cells have been considered as the next-generation clean energy sources [1]. However, incorporation of liquid solvents such as acetonitrile and iodide/triiodide redox mediators in the cell has been facing problems, for instance, solvent evaporation (reducing life-time), inconvenience in the module sealing, and carcinogenic concerning of chemicals used in the electrolyte. Alternatively, a quasisolid-like composite electrolyte turns out to be a solution of those problems [28]. Hiroki et al. found that incorporation of carbon materials in a molten salt could improve the electric conductivity of the quasisolid-like electrolyte, which also had better photon conversion efficiency [3]. In the present work, Cu@C (copper encapsulated in the carbon shell) nanoparticles were dispersed in a molten salt (1,2-dimethyl-3-propylimidazolium iodide (DMPII)) as a nanocomposite electrolyte utilized in DSSCs. X-ray absorption near edge structure (XANES) spectroscopy was also used to reveal speciation of copper in the $\mathrm{Cu} @ \mathrm{C}$ nanoparticles dispersed in the molten salt.

\section{Experimental}

The core-shell $(\mathrm{Cu} @ \mathrm{C})$ nanoparticles were synthesized via carbonization of $\mathrm{Cu}^{2+}$-starch complexes at $673 \mathrm{~K}$ for 12 hours. By TEM and XRD, it is clear that the $\mathrm{Cu} @ \mathrm{C}$ nanoparticles have the (core) metallic copper $(\mathrm{Cu})$ sizes of 7-20 nm. The Cu@C nanoparticles (0.3-10wt\%) were dispersed in the DMPII (Solaronix SA, Switzerland) (0.6 M) in an electrolyte which contains $0.1 \mathrm{M}$ of LiI (Aldrich, USA), $0.05 \mathrm{M}$ of $\mathrm{I}_{2}$ (Riedel-de Haën, Germany), and $0.5 \mathrm{M}$ of 4-tertbutylpyridine (Aldrich, USA) in acetonitrile (Mallinckrodt, USA).

To fabricate the photoelectrode of the DSSC, $6 \mathrm{~g}$ of nanosize $\mathrm{TiO}_{2}$ (P25 nanograde, Degussa, Germany) were mixed with a solution containing $0.1 \mathrm{~mL}$ of Triton X100 (Sigma-Aldrich, USA), $0.2 \mathrm{~mL}$ of acetylacetone (Fluka, Switzerland), and $10 \mathrm{~mL}$ of deionized water to yield a $\mathrm{TiO}_{2}$ paste. Three drops of the $\mathrm{TiO}_{2}$ paste were spread on the Scotch magic tape- $(3 \mathrm{M})$ masked fluorine-doped tin oxide substrate ( $8 \mathrm{ohm} / \mathrm{square}$, Solaronix SA, Switzerland) $(2.5 \mathrm{~cm}$ $\times 2.5 \mathrm{~cm}$ ) by the doctor-blade method. The as-coated glass was dried and scratched out for a working area of $0.25 \mathrm{~cm}^{2}$, preheated at $323 \mathrm{~K}$ for 15 minutes, and calcined at $723 \mathrm{~K}$ for 


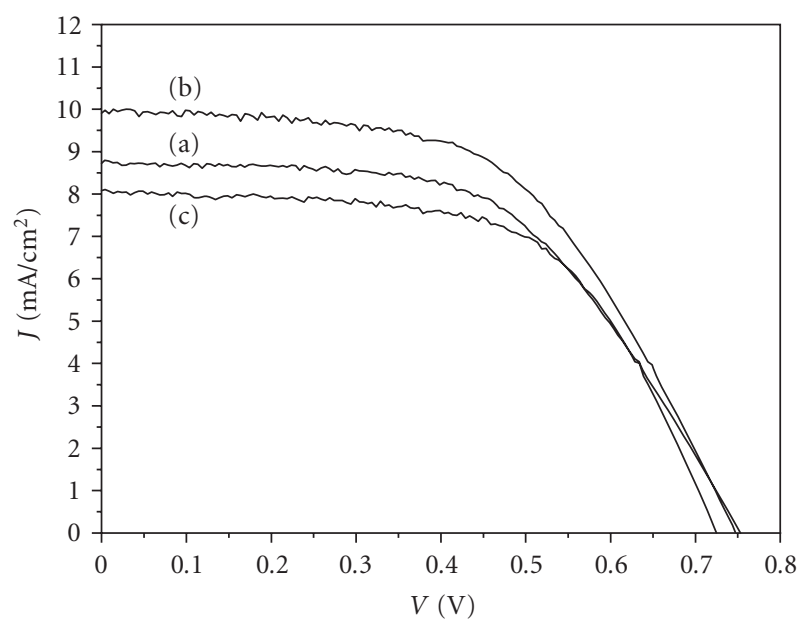

Figure 1: Photocurrent densit ( $J$ ) of the DSSC containing (a) 0, (b) 1, and (c) 3\% of the $\mathrm{Cu@C} \mathrm{nanoparticles} \mathrm{(} \mathrm{Cu}$ size =7 nm) dispersed in the molten salt.

30 minutes. The $\mathrm{TiO}_{2}$-coated glass was immersed in a $3 \times$ $10^{-4} \mathrm{M}$ of N3 (cis-di(thiocyanato)- $N, N^{\prime}$-bis $\left(2,2^{\prime}\right.$-bipyridyl4,4'-dicarboxylate) ruthenium(II), ruthenium 535, Solaronix SA, Switzerland) anhydrous ethanol solution for 24 hours in the dark. The stained photoelectrode was dried in $\mathrm{N}_{2}$ for the assemblage of the DSSC.

The counterelectrode was prepared by distribution of three drops of $\mathrm{H}_{2} \mathrm{PtCl}_{6} \cdot 6 \mathrm{H}_{2} \mathrm{O}$ (Alfa Aesar, USA) on the conducting tin oxide electrode $(10 \mathrm{ohm} / \mathrm{square}$, RITEK, Taiwan) with a spin-coater (SP-M1-S, APISC, Taiwan) at $1500 \mathrm{rpm}$ for 15 seconds. The electrode was preheated at $323 \mathrm{~K}$ for 10 minutes and calcined at $658 \mathrm{~K}$ for 10 minutes.

The photoelectrode and counterelectrode were sandwiched together with a $60 \mu \mathrm{m}$ thick hot-melt thermal foil (SO-SX1170, Solaronix SA, Switzerland) as a spacer. The $\mathrm{Cu} \mathrm{C}$ dispersed electrolyte was introduced into the cell and sealed with $A B$ epoxy that was cured for 30 minutes. $A$ $300 \mathrm{~W}$ xenon arc lamp solar simulator (no. 91160A, Oriel, USA) conjugated with an AM 1.5 Globe filter (no. 59044, Oriel, USA) was employed to measure the $I-V$ characteristics of the quasisolid-state DSSC. The illumination was fixed at $100 \mathrm{~mW} / \mathrm{cm}^{2}$ using a reference solar cell and meter (no. 91150, Oriel, USA). In each experiment, at least five solar cell measurements were carried out to ensure the acceptable data being obtained.

The copper K-edge XANES spectra of the Cu@C nanoparticles dispersed (1-10\%) in the electrolyte were determined on the Wiggler BL17C1 beam line at the Taiwan National Synchrotron Radiation Research Center. The electron storage ring was operated at energy of $1.5 \mathrm{GeV}$. A Si(111) double-crystal monochromator was used for selection of energy with an energy resolution $(\triangle E / E)$ about $1.9 \times$ $10^{-4}(\mathrm{eV} / \mathrm{eV})$. The incident photon energy was calibrated using a standard copper foil with a characteristic absorption edge at $8979 \mathrm{eV}$. The XANES spectra of copper in the $\mathrm{Cu} @ \mathrm{C}$ nanoparticles were analyzed with the UWXAFS 3.0 program [9]. Semiquantitative analyses of the XANES spectra of copper were conducted by the least-square fitting of linear

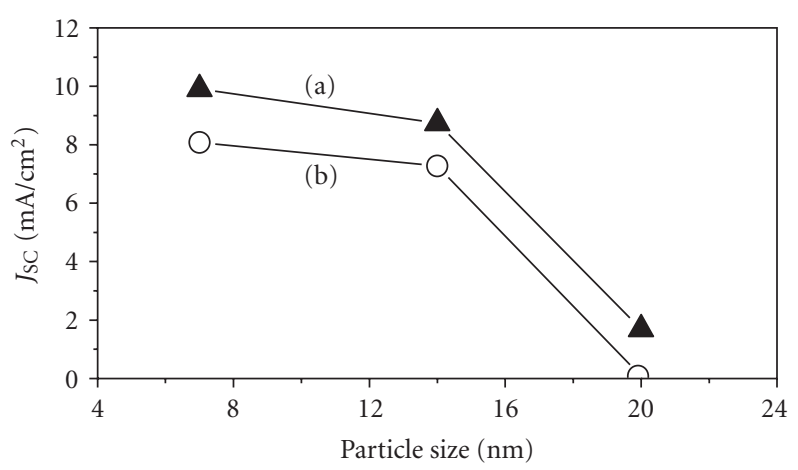

(a)

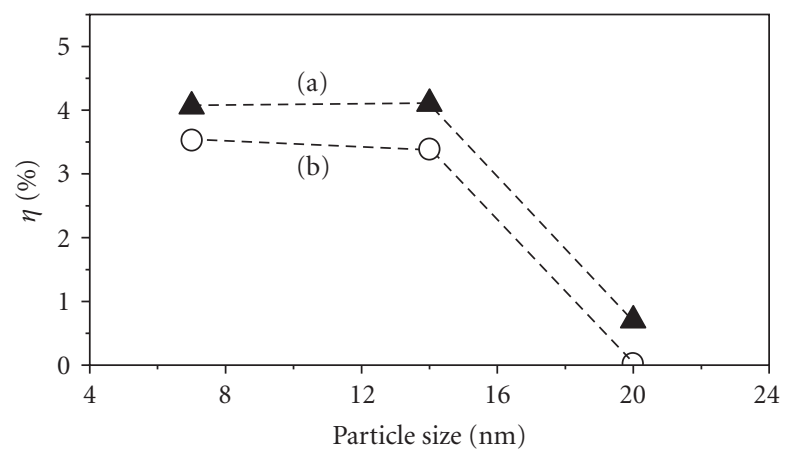

(b)

FIGURE 2: Dependence of $\mathrm{Cu}$ sizes in the Cu@C nanoparticles ( (a) 1 and (b) 3\%) dispersed molten salt in the electrolyte on the shortcircuit photocurrent density $\left(J_{\mathrm{SC}}\right)$ and conversion efficiency $(\eta)$ of the DSSC.

combinations of standard spectra (Cu (Merck, Germany, 99.7\%), $\mathrm{Cu}_{2} \mathrm{O}$ (Aldrich, USA, 97\%), $\mathrm{CuO}$ (Merck, Germany, 99\%), and NanoTeK ${ }^{\mathrm{R}} \mathrm{CuO}$ (Kanto, Japan, 99.3\%)) to the spectra of samples. On the average, an uncertainty limit of $5 \%$ corresponds to an error of about c.a. $2.0 \%$ in the fitting results.

\section{Results and Discussion}

The $I-V$ characteristics of the quasisolid-state DSSC enhanced with the $\mathrm{Cu} @ \mathrm{C}$ nanoparticles $(\mathrm{Cu}$ size = $7 \mathrm{~nm})$ dispersed molten salt (DMPII) in the electrolyte are shown in Figure 1. The DSSC containing 1\% of the Cu@C nanoparticles dispersed in the molten salt exhibits a maximum short-circuit photocurrent density $\left(J_{\mathrm{SC}}=9.910 \mathrm{~mA} / \mathrm{cm}^{2}\right)$, moderate open-circuit photovoltage $\left(V_{\mathrm{OC}}=0.748 \mathrm{~V}\right)$ and an enhancement (about 11\%) of the conversion efficiency $(\eta=$ 4.06\%). A greater fraction (3\%) of the Cu@C nanoparticles, on the contrary, leads to a decrease of the conversion efficiency $(\eta=3.53 \%)$.

Figure 2 shows the dependence of the $\mathrm{Cu}$ sizes in the core of the Cu@C nanoparticles on $J_{S C}$ and $\eta$ of the DSSC. It seems that $J_{\mathrm{SC}}$ and $\eta$ decrease with an increase of the $\mathrm{Cu}$ size in the Cu@C nanoparticles. For the large Cu@C nanoparticles$(\mathrm{Cu}$ size $=20 \mathrm{~nm})$ dispersed molten salt in the DSSC, the $J_{\mathrm{SC}}$ (Figure 2(a)) and $\eta$ (Figure 2(b)) are dramatically reduced. 


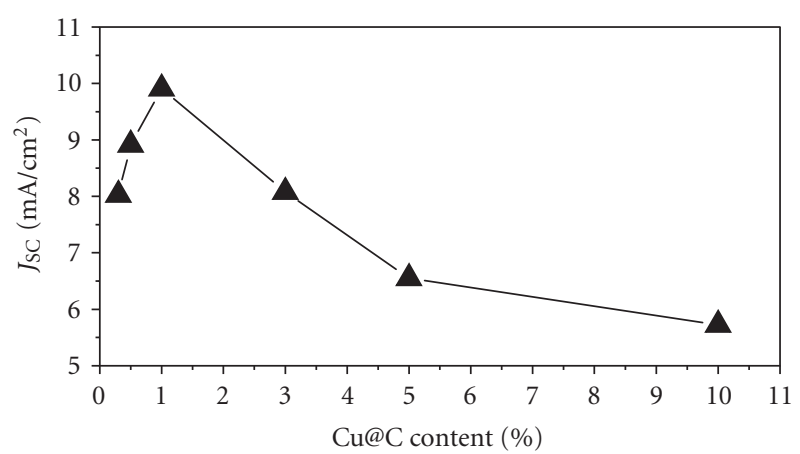

(a)

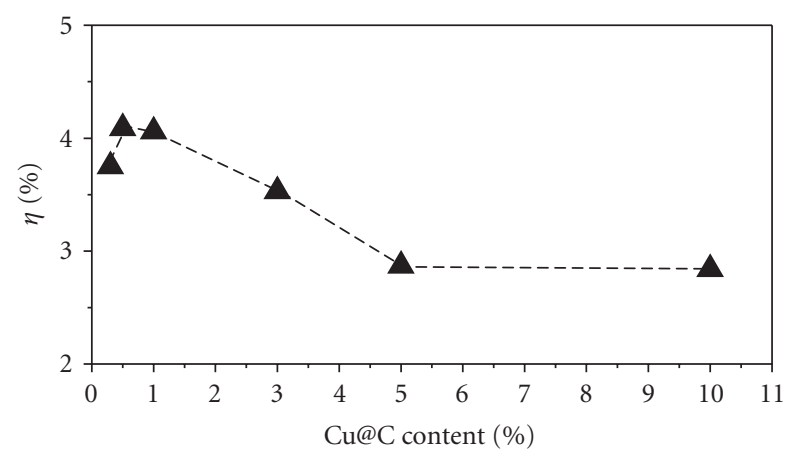

(b)

Figure 3: Dependence of fractions of Cu@C nanoparticles- $(\mathrm{Cu}$ size $=7 \mathrm{~nm}$ ) dispersed in the molten salt on the (a) short-circuit photocurrent density $\left(J_{\mathrm{SC}}\right)$ and $(\mathrm{b})$ conversion efficiency $(\eta)$ of the DSSC.

In Figure 3, the DSSC containing 1\% of the $\mathrm{Cu@C}(\mathrm{Cu}$ size $=7 \mathrm{~nm}$ ) nanoparticles dispersed in the molten salt in the electrolyte has a desirable $J_{\mathrm{SC}}\left(9.910 \mathrm{~mA} / \mathrm{cm}^{2}\right)$ and $\eta$ $(4.06 \%)$. In the separate experiments, we also found that the self-diffusion coefficients of cations and anions in a room temperature ionic liquid $\left([\mathrm{bmim}]\left[\mathrm{BF}_{4}\right]\right)$ dispersed with 0.08\% of Cu@C nanoparticles were increased by 4.3-6.6 times [10]. The electrical conductivity of the $\mathrm{Cu@C} \mathrm{dispersed}$ [bmim] $\left[\mathrm{BF}_{4}\right]$ was increased by as high as 3.7 times in comparison with that without the Cu@C nanoparticles [10]. Nevertheless, in the present work, it is found that greater fractions (3-10\%) of the Cu@C nanoparticles dispersed in the molten salt, on the contrary, may interfere the internal electron transportation routes or result in the electron back transportation from photoelectrode to counterelectrode, which cause a poor performance (lower $J_{S C}$ and $\eta$ ) of the DSSC. A short-circuit in the presence of a large amount of carbon nanotubes and/or carbon nanoparticles in the quasisolid-state DSSCs was also found by Usui et al. [3].

Molecular-scale data of select compounds in the complex matrix determined by XANES turn out to be very useful in revealing chemical structure and composition of key species in the reaction pathways [11, 12]. Figure 4 illustrates the XANES spectra of copper in the Cu@C nanoparticlesdispersed molten salt. The $\mathrm{Cu@C} \mathrm{nanoparticles} \mathrm{contain}$ mainly nanosize $\mathrm{Cu}(63 \%), \mathrm{Cu}_{2} \mathrm{O}(13 \%)$, and $\mathrm{CuO}(24 \%)$. Note that after the repeatedly efficiency measurements of

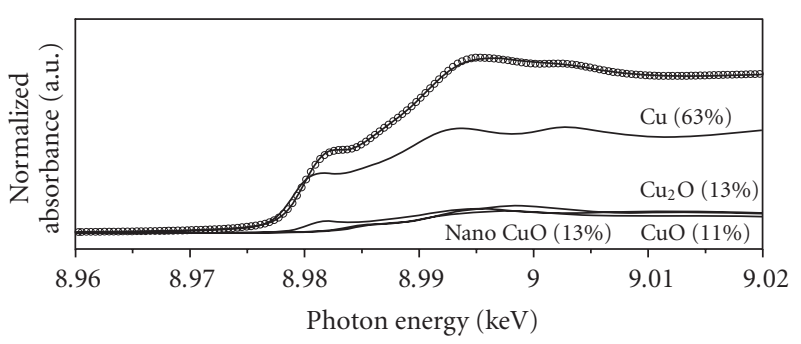

(a)

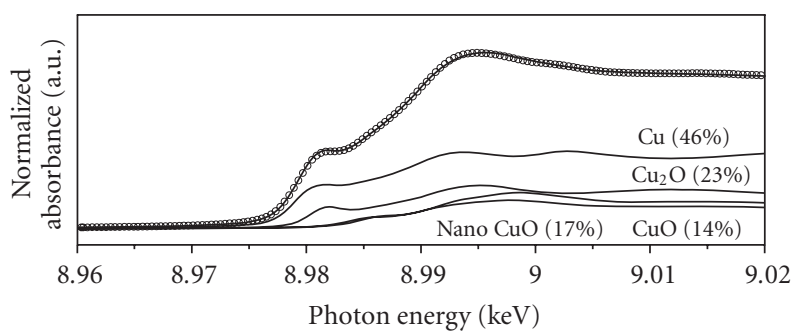

(b)

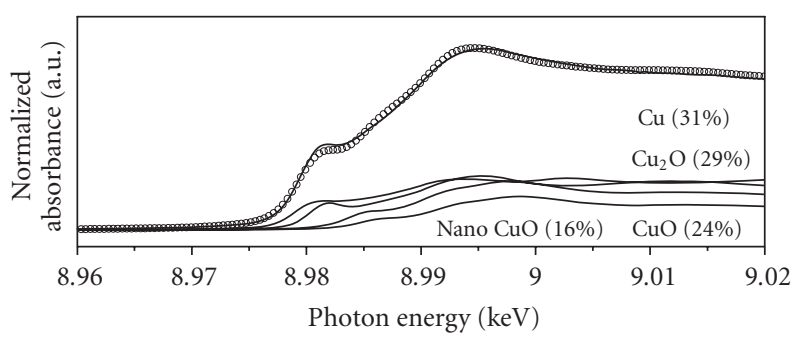

(c)

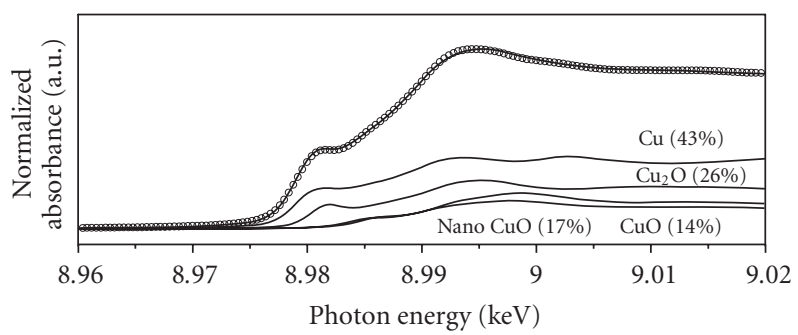

(d)

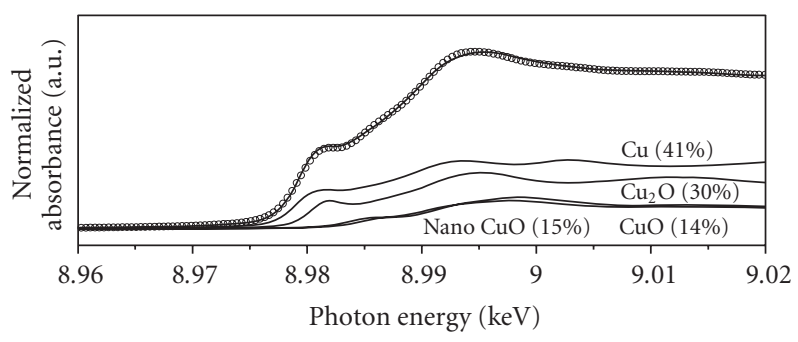

(e)

FIgURE 4: The least-square fitted XANES spectra of copper in the Cu@C nanoparticles-(Cu size = 7 nm) (fractions of (a) 0, (b) 1, (c) 3 , (d) 5 , and (e) $10 \%$ ) dispersed in the molten salt. 
the quasisolid-state DSSC, in the presence of $0.05 \mathrm{M}$ of $\mathrm{I}_{2}$ (in the electrolyte), $17-32 \%$ of $\mathrm{Cu}$ encapsulated in the carbon shells are oxidized to $\mathrm{Cu}_{2} \mathrm{O}(10-17 \%)$ and $\mathrm{CuO}(5-$ $17 \%$ ) (Figure 4). The oxidation of $\mathrm{Cu}$ with $\mathrm{I}_{2}$ may interfere the internal electron transportation routes in the DSSC. As shown in Figure 3, greater fractions (3-10\%) of the $\mathrm{Cu} @ \mathrm{C}$ nanoparticles dispersed in the molten salt in the electrolyte result in a poor performance (lower $J_{\mathrm{SC}}$ and $\eta$ ) of the DSSC.

Generally, the ratio of surface-to-total atoms for a $\mathrm{Cu}$ nanoparticle having a size of $7 \mathrm{~nm}$ is about 0.11 . It seems that oxidation occurs mainly on the surfaces of the $\mathrm{Cu}$ nanoparticles, and further oxidation down to subsurfaces may be limited to about $40 \%$ of the total $\mathrm{Cu}$ atoms. The $\mathrm{CuO}$ or $\mathrm{Cu}_{2} \mathrm{O}$ layer on the surfaces of the core $\mathrm{Cu}$ in the $\mathrm{Cu} @ \mathrm{C}$ may not perturb directly the electron transportation routes in the DSSC. Alternatively, the electron-rich surfaces of the carbon shell consisted of diamond and graphite carbons may play the main role in the electrical conduction.

\section{Conclusions}

Enhancements of the short-circuit photocurrent density $\left(J_{\mathrm{SC}}\right)$ and solar conversion efficiency $(\eta)$ of the DSSC with the Cu@C nanoparticles-dispersed molten salt-conjugated electrolyte have been observed. The DSSC containing 1\% of the $\mathrm{Cu} @ \mathrm{C}(\mathrm{Cu}$ size = $7 \mathrm{~nm})$ nanoparticles dispersed in the molten salt has a desirable $J_{\mathrm{SC}}\left(9.910 \mathrm{~mA} / \mathrm{cm}^{2}\right)$ and $\eta(4.06 \%)$. Greater fractions (3-10\%) of the Cu@C nanoparticles dispersed in the molten salt cause a poor performance (lower $J_{\mathrm{SC}}$ and $\eta$ ) of the DSSC possibly due to interference of the normal internal electron transportation routes in the DSSC by oxidation of $\mathrm{Cu}$ with $\mathrm{I}_{2}$ originally in the electrolyte.

\section{Acknowledgments}

The financial supports of the Taiwan National Science Council, Bureau of Energy, the Excellence Project of the National Cheng Kung University, and National Synchrotron Radiation Research Center are gratefully acknowledged.

\section{References}

[1] B. O’Regan and M. Grätzel, "A low-cost, high-efficiency solar cell based on dye-sensitized colloidal $\mathrm{TiO}_{2}$ films," Nature, vol. 353, no. 6346, pp. 737-740, 1991.

[2] P. Wang, S. M. Zakeeruddin, P. Comte, I. Exnar, and M. Grätzel, "Gelation of ionic liquid-based electrolytes with silica nanoparticles for quasi-solid-state dye-sensitized solar cells," Journal of the American Chemical Society, vol. 125, no. 5, pp. 1166-1167, 2003.

[3] H. Usui, H. Matsui, N. Tanabe, and S. Yanagida, "Improved dye-sensitized solar cells using ionic nanocomposite gel electrolytes," Journal of Photochemistry and Photobiology A, vol. 164, no. 1-3, pp. 97-101, 2004.

[4] T. Kato, T. Kado, S. Tanaka, A. Okazaki, and S. Hayase, "Quasi-solid dye-sensitized solar cells containing nanoparticles modified with ionic liquid-type molecules," Journal of the Electrochemical Society, vol. 153, no. 3, pp. A626-A630, 2006.
[5] B. Xue, H. Wang, Y. Hu, et al., "Highly efficient dye-sensitized solar cells using a composite electrolyte," Comptes Rendus Chimie, vol. 9, no. 5-6, pp. 627-630, 2006.

[6] T. Katakabe, R. Kawano, and M. Watanabe, "Acceleration of redox diffusion and charge-transfer rates in an ionic liquid with nanoparticle addition," Electrochemical and Solid-State Letters, vol. 10, no. 6, pp. F23-F25, 2007.

[7] Z. Lan, J. Wu, D. Wang, S. Hao, J. Lin, and Y. Huang, "Quasisolid-state dye-sensitized solar cells based on a sol-gel organicinorganic composite electrolyte containing an organic iodide salt," Solar Energy, vol. 81, no. 1, pp. 117-122, 2007.

[8] M. Berginc, M. Hočevar, U. O. Krašovec, A. Hinsch, R. Sastrawan, and M. Topič, "Ionic liquid-based electrolyte solidified with $\mathrm{SiO}_{2}$ nanoparticles for dye-sensitized solar cells," Thin Solid Films, vol. 516, no. 14, pp. 4645-4650, 2008.

[9] E. A. Stern, M. Newville, B. Ravel, Y. Yacoby, and D. Haskel, "The UWXAFS analysis package: philosophy and details," Physica B, vol. 208-209, pp. 117-120, 1995.

[10] F. L. Chen, I. W. Sun, H. P. Wang, and C. H. Huang, "Nanosize copper dispersed ionic liquids as an electrolyte of new dyesensitized solar cells," Journal of Nanomaterials, in press.

[11] H.-L. Huang, H. P. Wang, G.-T. Wei, I.-W. Sun, J.-F. Huang, and Y. W. Yang, "Extraction of nanosize copper pollutants with an ionic liquid," Environmental Science \& Technology, vol. 40, no. 15, pp. 4761-4764, 2006.

[12] H. H. Hsu, J. H. Huang, H. P. Wang, and C. J. G. Jou, "Speciation of zinc in nano phosphor particulars abstracted in an ionic liquid," Radiation Physics and Chemistry, vol. 75, no. 11, pp. 1930-1933, 2006. 



The Scientific World Journal

Submit your manuscripts at

http://www.hindawi.com

\section{World Journal}

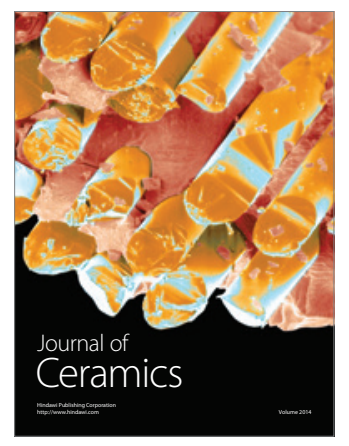

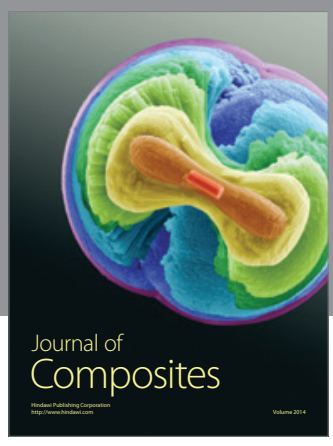
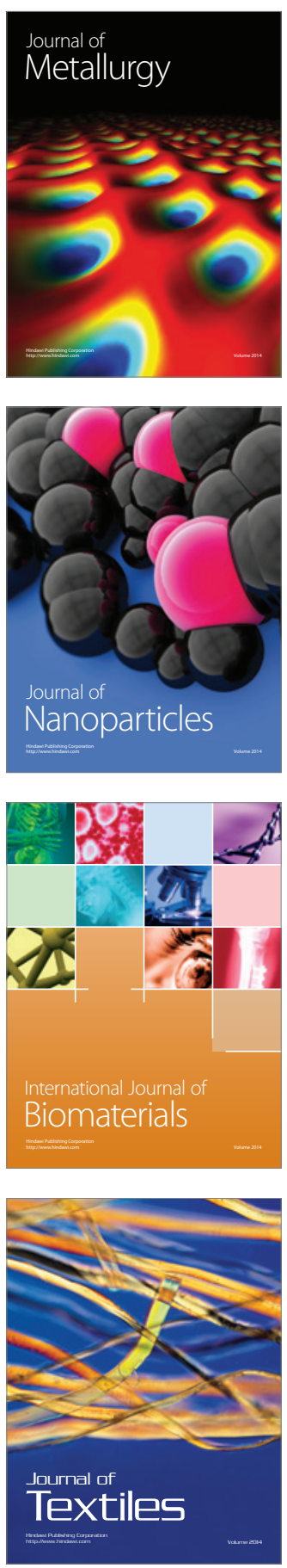